2. Zagli G, Cianchi G, Degl'innocenti S, et al. Treatment of fournier's gangrene with combination of vacuum-assisted closure therapy, hyperbaric oxygen therapy, and protective colostomy. Case Rep Anesthesiol 2011;2011:430983.

3. Huettinger P, Dunst-Huemer KM, Huemer GM. The VAC-Basket for Easy Fixation of Scrotal Skin Grafts. Arch Plast Surg 2012;39:667-8.

4. Djedovic G, Engelhardt TO, Rieger UM, et al. The sandwich technique for vacuum-assisted wound dressing application in the urogenital region: a safe, time-sparing and reliable method. Singapore Med J 2012;53:294-5.

5. von Ruden C, Benninger E, Mayer D, et al. Bogota-VAC: a newly modified temporary abdominal closure technique. Eur J Trauma Emerg Surg 2008;34:582-6.

\section{Facial Cushioning during Prolonged Surgery in the Upper Torso}

Jonathan Bank, Julie E. Park

Section of Plastic and Reconstructive Surgery, Department of Surgery, University of Chicago Medical Center, Chicago, IL, USA

Correspondence: Julie E. Park

Section of Plastic and Reconstructive Surgery, Department of Surgery, University of Chicago Medical Center, 5841 S. Maryland Avenue, MC 6035, Chicago, IL 60637, USA

Tel: +1-773-702-6302, Fax: +1-773-702-1634,E-mail: jpark@surgery.bsd.uchicago.edu

No potential conflict of interest relevant to this article was reported.

Received: 18 Feb 2014 • Revised: 4 Mar 2014 • Accepted: 6 Mar 2014 pISSN: 2234-6163 • elSSN: 2234-6171

http://dx.doi.org/10.5999/aps.2014.41.4.423 • Arch Plast Surg 2014;41:423-424

Copyright (C) 2014 The Korean Society of Plastic and Reconstructive Surgeons

This is an Open Access article distributed under the terms of the Creative Commons Attribution Non-Commercial License (http://creativecommons.org/licenses/by-nc/3.0/) which permits unrestricted non-commercial use, distribution, and reproduction in any medium, provided the original work is properly cited.

Safe patient positioning is a basic tenet of surgical preparation. $\mathrm{Nu}-$ merous publications describe the principles of protecting areas of the body that may be prone to injury from pressure or stretch [1-4]. Undoubtedly, many surgeons and anesthesiologists have developed their own modifications to accommodate for their particular needs and comfort, while maintaining the fundamental elements necessary to provide for a safe surgical environment.

We herein describe a simple method to guard the face from direct pressure during surgery of the upper torso. The need arose performing autologous breast reconstruction that required prolonged operating in the upper chest. This incurs the risk of the operating surgeon and assistant to inadvertently rest their elbows on the patient face,
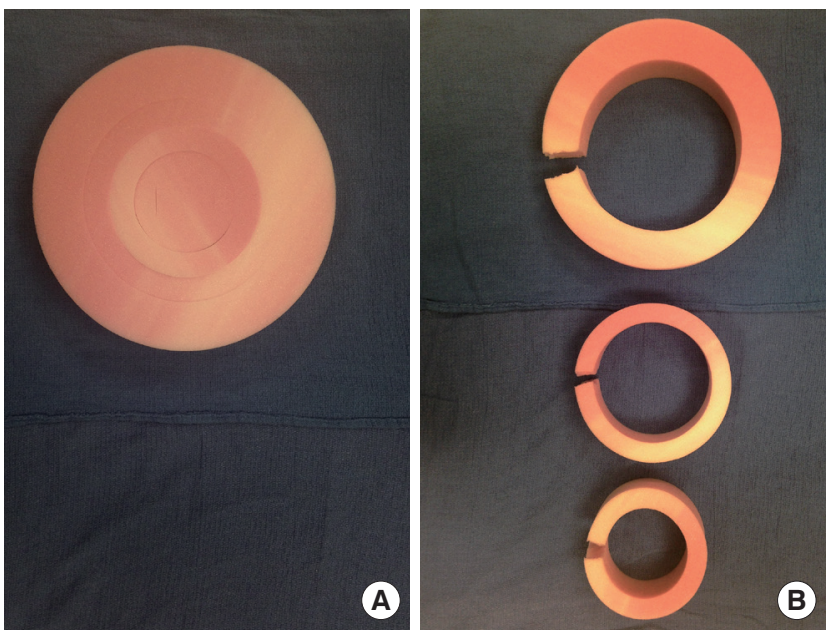

Fig. 1. The Devon Whole-in-One (Kendall) headrest (A) and (B) bthe headrest disassembled into its components as described in the text.

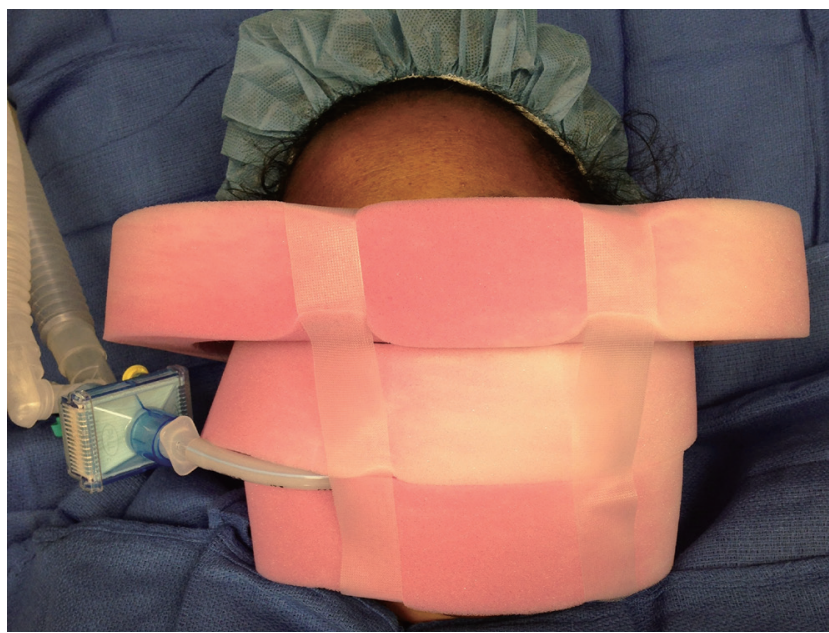

Fig. 2. The headrest components separated and placed on the patient's face during surgery.

risking displacement of the endotracheal tube and potentially injuring the eyes, nose, and mouth.

The Devon Whole-in-One (Kendall) headrest is typically used to cushion the patient's head in the supine position. It is made of nontoxic, latex-free foam, and can be adjusted to fit by removing portion of the foam as needed. We use the foam to pad the patient's face during surgery in the technique described below. Other headrests and foam (such as "egg crates") tend to be bulky and may impede surgical access by partially obstructing the surgical field.

The headrest is comprised of four circular components of varying thicknesses. The inner core is discarded. The outer ring is torn in half and used to cover the eyes like sunglasses. The second layer is cut and placed over the nose, with a slit made to accommodate for the endotracheal tube. The third layer is split and placed over the chin (Figs. 1, 2). 
The retail cost of a box of 36 units ranges between $\$ 70$ and $\$ 80$, or roughly $\$ 2$ per headrest. The low cost, ease of use, malleability and high availability of this device makes it an ideal solution for a common problem.

\section{References}

1. Shermak M, Shoo B, Deune EG. Prone positioning precautions in plastic surgery. Plast Reconstr Surg 2006;117:1584-8.

2. Ellsworth IV WA, Iverson RE. Patient safety in the operating room. Semin Plast Surg 2006;20:214-8.

3. Knight DJW, Mahajan RP. Patient positioning in anaesthesia. Contin Educ Anaesth Crit Care Pain 2004;4:160-3.

4. Roth S, Thisted RA, Erickson JP, et al. Eye injuries after nonocular surgery. A study of 60,965 anesthetics from 1988 to 1992 . Anesthesiology 1996;85:1020-7. 